\title{
El abuso del Derecho
}

Enrique Cuentas Ormachea

Una ley universal que rige los fenómenos sociales y físicos es su constante mutación. El fenómeno jurídico no escapa a esta ley y así como la sociedad cambia su organización en el decurso del tiempo, los derechos que rigen la vida social también experimentan un continuo movimiento de renovación.

Como bien dijo León Duguit "El Derecho no es tanto la obra del legislador como el producto constante y espontáneo de los hechos".

"Las leyes, los Códigos pueden permanecer rígidos en sus textos, pero por la fuerza de las cosas, bajo la presión de los hechos y por la necesidad práctica de regirlos surgen nuevas normas que originan a su vez, instituciones jurídicas nuevas".

Los textos legales van quedando sin vigencia y, por eso, es necesario $y$ urgente ponerlos a tono con las nuevas instituciones. Puede afirmarse, pues, que conforme van cambiando las relaciones económicas y sociales deben cambiar las normas que las regulan. Este es el motivo que determina la renovación de los códigos y las leyes.

1 León Duguit. Transformaciones del Derecho Privado. París, 1927. 
La teoría del Abuso del Derecho es el resultado de tales cambios. Surge como una figura jurídica resultante de la evolución del derecho que refleja la evolución de la vida social donde surgen nuevas instituciones, nuevas relaciones sociales y, por ende, nuevas relaciones jurídicas, nuevas concepciones del derecho.

\section{Discusiones doctrinarias sobre la naturaleza del acto abusivo.}

Los tratadistas de derecho están de acuerdo en que la vida en sociedad impone la represión de la mala fe, del egoísmo y de actos, aun triviales, que origine una persona en el ejercicio de sus derechos, en detrimento de terceros. Asimismo lo están en la necesidad de que el derecho positivo debe acoger esa represión mediante una fórmula que solucione satisfactoriamente el conflicto de intereses entre el agente que ejerce su derecho en forma abusiva y el tercero que queda afectado por ese ejercicio. Como dice Raymundo Saleilles surge la necesidad de un correctivo indispensable para conciliar los derechos del individuo con los de la sociedad.

Toda norma jurídica se refiere a la actividad del hombre frente a los demás, es decir implica una relación entre dos sujetos: el activo y el pasivo, o sea el sujeto que tiene el deber para con alguien y el sujeto, en favor de quien se tiene el deber. La Filosofía del Derecho distingue dos fases en el fenómeno jurídico: la objetiva y la subjetiva, lo que nos conduce a distinguir dos aspectos de ese fenómeno, el derecho subjetivo o sea el conjunto de facultades para ser o exigir todo aquello que la ley o la autoridad establecen en favor del sujeto de derecho; y el derecho objetivo o sea el conjunto de normas para ejercitar dichas facultades, o, como dice Vanni "el conjunto de normas generales impuestas a la acción humana, en sus relaciones externas y apoyadas por la autoridad del Estado, para garantizar los fines del individuo y de la sociedad". Lo que quiere decir que el Derecho como norma o sea el derecho objetivo se concibe como el conjunto de reglas que determinan y regulan el ejercicio de las facultades y el cumplimiento de los deberes que integran el derecho subjetivo.

Lo expuesto nos lleva a la conclusión de que el ejercicio del derecho determina que los individuos sean, al mismo tiempo, sujetos activos y sujetos pasivos. 
El derecho y su ejercicio nos permiten, pues, distinguir dos aspectos:

a) Como atribución o facultad que corresponde a su titular; y, b) como la forma o modo cómo se hace uso de esa facultad. La noción del acto abusivo o abuso del derecho surge de esta distinción.

Todo derecho subjetivo tiene su origen en un hecho humano ya que el hombre es el único sujeto de derecho.

El derecho subjetivo lo apreciamos en dos momentos: a) el derecho en potencia o sea el goce del derecho, que es su manifestación estática; b) el momento dinámico en que ese derecho entra en actividad, que es cuando se ejerce el derecho o cuando se le haga actuar. Una de las formas de este momento es la acción que, como dice Vanni, "es el medio técnico para hacer valer un derecho subjetivo en juicio".

El abuso del Derecho se presenta en el momento dinámico, es decir cuando se ejercita la facultad que nos confiere la ley. Por eso resulta más propio decir "ejercicio abusivo del derecho" que abuso del derecho, pero la doctrina y la jurisprudencia han optado por esta última expresión, criterio que respetamos.

El derecho en ejercicio tiene una limitación objetiva y otra subjetiva. Objetiva, en cuanto no puede pasar de los límites que la ley señala; $y$, subjetiva, por cuanto debe perseguir con su ejercicio una finalidad social o económica compatible con la razón y el fundamento de la norma que garantiza ese derecho. Pues bien, el Abuso del Derecho se pone de manifiesto cuando no se respetan esos límites.

\section{III}

La determinación de la naturaleza del acto abusivo ha motivado disparidad de criterios, que resumiremos a continuación.

Así, Marcel Planiol equipara el abuso del derecho con el acto ilícito. Dice que si alguien usa de su derecho el acto es lícito; y que si traspasa

2 Icilio Vanni. Filosofía del Derecho. Trad. J.B. de Lavalle, A. Cáceres Olazo. Bs. Aires, 1920. 
su derecho el acto es ilícito y el sujeto obra sin derecho; que el derecho cesa donde el abuso comienza; y que, el acto abusivo, puesto que es ilícito, no puede importar el ejercicio de un derecho. ${ }^{3}$

Pero debemos advertir que hay diferencia entre uno y otro. Anotamos las siguientes: a) El acto ilícito importa una violación de la ley, pues el que obra ilícitamente obra sin derecho o contra derecho; el acto abusivo importa el ejercicio de un derecho por el titular mismo. b) El acto ilícito implica dolo, culpa o negligencia como regla general; en cambio, para el abuso, no es de su esencia la existencia de tales elementos; la intención maliciosa es, a veces, elemento integrante del acto abusivo pero no es elemento esencial como en el acto ilícito. c) El daño que produce el acto ilícito repercute en el tercero; en cambio, el daño que produce el abuso puede referirse a la misma persona o a la colectividad, como el caso del propietario que por propia voluntad no cultiva su terreno.

Luego, no puede afirmarse que el abuso del derecho y el acto ilícito son idénticos.

También se ha confundido el abuso del derecho con el "conflicto de derechos", pues se afirma que, en todo caso, el abuso importa enfrentar un derecho con otro derecho de los que uno es excluido por el otro al que se le considera de mayor valor.

Un examen cuidadoso de ambas figuras jurídicas nos llevan a la conclusión de que hay diferencia entre una y otra. El conflicto de derechos surge cuando dos intereses jurídicamente protegidos se hallan en franca contraposición, v. gr. el caso del agredido que hace uso de su legítima defensa frente al agresor a quien lesiona para evitar ser lesionado, o el derecho del acreedor que pretende hacerse pago de una deuda frente al derecho del deudor que quedaría en la indigencia si la abonase. En el acto abusivo no hay conflicto de derechos pues no se trata de contraponer un derecho frente a otro derecho para establecer cuál es el más importante o cual tiene más valor; en el abuso del derecho de lo que se trata es de establecer si el agente puede o no hacer uso de la facultad que le concede la ley cuando ese ejercicio afecta a un tercero o al grupo social, es decir si el agente puede o no ejercitar su facultad jurídica dentro de los límites legales.

3 Marcel Planiol. Tratado Elemental de Derecho Civil. Tomo 2. París, 1925. 
Otra confusión en que se ha incurrido es la del Abuso del Derecho con la "responsabilidad emergente del riesgo". La responsabilidad por riesgo emana de una corriente innovadora del derecho según la cual éste debe mantener la armonía social, el orden jurídico evitando un desequilibrio patrimonial; es decir, si un individuo o un grupo en el ejercicio de una actividad permitida por la ley, que le produce un beneficio patrimonial, pone en peligro la vida o la salud y el bienestar de terceros (individuos o grupos) debe reparar los daños y perjuicios emergentes de su actividad. Basta que se derive un daño de la actividad lícita de una persona que se beneficia con esa actividad para que ésta tenga la obligación de reparar ese daño. Este principio funciona en el riesgo profesional derivado de los accidentes de trabajo, como se desprende de las normas establecidas en la Ley de Accidentes de Trabajo; también se aplica en los casos contemplados por los artículos $1144^{\circ}, 1145^{\circ} \mathrm{y}$ $1146^{\circ}$ del Código Civil así como en los accidentes de tránsito."

Pues bien, aunque la responsabilidad por riesgo y el abuso del derecho tienen de común que ambas acarrean responsabilidad a pesar de que entrañan una actividad lícita por tener un origen emanado de la ley, hay diferencia entre ellas. El abuso del derecho importa un uso anormal de éste; en cambio la responsabilidad por riesgo se produce cuando el uso de un derecho que deriva un beneficio a quien lo ejercita, crea un riesgo para tercero, por lo que el beneficiario debe soportar la incidencia derivada del ejercicio de ese derecho, lo que al decir de Josserand importa "una responsabilidad sin culpa o responsabilidad puramente objetiva" ". Habría abuso del derecho en el caso del empresario que en ejercicio de su libertad de industria y basado en su potencia económica, rebaja el precio de sus productos por debajo de su costo con el objeto de eliminar a un competidor; la responsabilidad por riesgo se produciría en el caso del industrial cuya usina desprende gases tóxicos que arruinan los sembríos próximos.

Mientras que en el riesgo no hay relación directa entre la gente responsable y el daño por el que responde, pues éste se produce accidentalmente es decir, involuntariamente, en el caso del abuso del dere-

* Los numerales citados en este trabajo son los del C.C. vigente hasta el 14 de noviembre de 1984 .

4 Luis Josserand. Del Abuso del Derecho. París, 1925. 
cho hay relación directa entre la gente que abusa de su derecho y el daño que emerge de su daño abusivo.

Además, el riesgo está expresa y taxativamente determinado por el legislador mientras el abuso escapa a toda previsión legislativa.

Como dice José Calvo Sotelo: "Prohibir el uso de un derecho porque acarrea un daño será tentar contra la libertad de su titular, suprimir la responsabilidad por riesgo sería injusto"s, lo que quiere decir que no podemos prohibir una actividad lícita aunque acarrea peligros, no solo porque esa actividad está amparada por la ley sino también porque de ella se deriva un beneficio social v. gr. el empresario produce artículos necesarios para el consumo. En cambio se debe sancionar el ejercicio de un derecho que se usa desviándolo del fin que se le reconoce o que está en contradicción con su destino económico o social.

\section{Fundamentación del Abuso del Derecho.}

El fundamento para reprimir el acto abusivo está en que ningún derecho es ilimitado, pues de ser así, no habría orden social posible. Aquel que tiene derechos frente a los demás integrantes de la sociedad, también tiene deberes para con ellos.

No puede existir un grupo social en que haya únicamente sujetos titulares de derecho así como tampoco puede haber una sociedad en que los hombres estén exclusivamente sujetos a cumplir deberes.

Debe tenerse presente que la limitación del derecho subjetivo de una persona no sólo está determinada por el interés de la sociedad o del Estado, sino, también, por el interés individual del titular de otro derecho subjetivo que necesita el respeto a su derecho para mantener su dignidad de persona o sea el ejercicio de sus facultades y poderes propios cuyo desconocimiento importaría la degradación de su estado de persona.

Como bien dice el ilustre tratadista nacional doctor José León Barandiarán: "El derecho no es absoluto, no puede ejercitarse de una manera que lastime los imperativos humanos de solidaridad social y de consideración intersubjetiva. De allí que se haya ido elaborando una

5 José Calvo Sotelo. El Abuso del Derecho. Madrid, 1920 
concepción en este orden de cosas que, en general, reciba consagración en el derecho moderno"6.

\section{Antecedentes legislativos}

La teoría del Abuso del Derecho que se ha concretado en fórmulas relativamente recientes, tiene raíces lejanas aun en expresiones del derecho consideradas individualistas a ultranza.

Así en el Derecho romano que consagró el absolutismo del derecho individual en la fórmula "qui jure suo utitur nominen loedit" (quien usa de su derecho no puede ser responsable) y que en su faz quiritaria devino en un "ius abutendi", fue atemperado por el derecho honorario admitiendo ciertas restricciones al derecho de propiedad como la prohibición de demoler una casa por el propietario con el sólo objeto de vender los materiales o la pérdida de la cuota que le correspondía al condómino si éste no contribuía con afrontar los gastos necesarios para la conservación de las servidumbres por falta de uso o la sustitución del compromiso del deudor de entregar a un esclavo a cambio de la entrega de su valor.

Otro antecedente se puede encontrar en las Leyes de las Partidas, que en la Ley 19, título XXXII, Partida III, dice: "Ca según que dixeron los sabios antiguos, maguer el ome haya de facer en lo suyo lo que quisiera, pero deuelo facer de manera que no faga daño nin tuerto a otro".

En la Edad Media se adopta el vocablo "aemulatio" que se usa, al igual que la frase "animus aemulandi", técnicamente por los juristas para designar "la intención de quien cumple ciertos actos, que aunque comprendidos normalmente en el ejercicio de su derecho, se emplea sin utilidad propia o con una mínima, con el fin de perjudicar a otro"'.

Pietro Bonfante hace referencia a la "teoría de los actos de emulación" como doctrina medioeval, según la que "se prohibían al propietario los actos por él cumplidos, con la maligna intención de perjudicar

6 José León Barandiarán. "Comentarios al Código Civil Peruano". Rev. Derecho y Ciencias Políticas. Año XII. No2.

7 Cristóforo Astorni. "Emulazione". Dizionario Pratico del Dirito Privatto. Edit. Vallendi. Milán, s/f. 
a otro, animus nocendi, con poca o ninguna utilidad propia” v. gr. el propietario que edifica un muro en su fundo sin necesidad inmediata, tan sólo para privar de luz o de la vista de un panorama amplio al vecino. Los juristas medioevales denominaban a estos actos "ad emulationem", de donde viene el nombre de la teoria. ${ }^{8}$

Para Marcel Planiol no era nueva la teoría del Abuso del Derecho, pues sus orígenes se pueden situar en la rica y minuciosa elaboración del derecho medioeval que inclusive tuvo alguno de los caracteres que actualmente suscitan controversias entre los especialistas como el ejercicio de un derecho subjetivo sin utilidad para su titular, o con una utilidad insignificante y con el designio de perjudicar a terceros.

El Código Civil napoleónico de 1804, de tendencia eminentemente individualista, si bien consagra el derecho de propiedad como el derecho de gozar y disponer de las cosas del modo más absoluto, tiene el agregado "a condición de que no se haga de ellas un uso prohibido por las leyes o reglamentos", lo que importa la posibilidad de la limitación en su ejercicio. Ya anotamos anteriormente que, poco después de la promulgación del Código Civil de 1804, la jurisprudencia francesa sancionó, en varios casos, el uso abusivo de los derechos, criterio que sigue vigente.

Lo expuesto nos lleva a la conclusión de que el convencimiento de la necesidad de reprimir esta clase de actos, cuando se ejercitan en forma abusiva, es muy antigua. Inclusive la literatura jurídica ha encontrado en alguna producción de escritores o dramaturgos situaciones vinculadas con el abuso del derecho, como el caso de Shylock en "El Mercader de Venecia" de Shakespeare, cuando pretende exigir a Antonio el cumplimiento de una cláusula del contrato estipulado con el solo propósito de perjudicarlo y sin una necesidad o interés legítimo.

\section{Fundamentos}

En el derecho contemporáneo, los criterios más diversos se han expuesto por los tratadistas para fundamentar el concepto de Abuso del De-

8 Pietro Bonfante. Instituciones de Derecho Romano, Atheneum, Roma, 1928. 
recho. Nos vamos a referir a los tres más importantes: la intención de dañar la falta de un interés serio y legítimo y la desviación del derecho de su función social.

La intención de dañar a que aluden Josserand y Porcherot ${ }^{9}$, incide en caracterizar el abuso del derecho por el móvil del acto constituido por "la intención de perjudicar". No interesa que esa intención sea el único móvil del acto o el motivo preponderante del mismo. Este criterio se apoya en que la garantía para ejercitar nuestro derecho no se nos otorga para que dañemos a otros; si lo hacemos estamos abusando de nuestro derecho. Pero la crítica ha puesto de manifiesto la insuficiencia de este criterio. Se le ha objetado porque no ofrece un punto de vista seguro y claro para distinguir el abuso donde no lo hay, como dice Planiol, "la idea es generosa pero no responde a la realidad" pues la vida social importa un conflicto de intereses contrapuestos, que el derecho trata de deslindar protegiendo a unos y negando garantía a otros, de acuerdo con la organización social existente. Por eso resulta difícil establecer si un acto se ha ejercitado con intención de dañar, ya que el mismo puede resultar dañino para unos y generoso para otros. Dice, además, Planiol que está bien que la moral sienta como un deber la generosidad y el altruismo para los demás, pero el jurista no puede escapar a la realidad social en la que los hombres se desenvuelven tratando de imponer su derecho unos a otros, perjudicando aquéllos a éstos. Además se objeta este criterio porque importa una indagación algo agnóstica sobre los propósitos o intenciones de quien ejercita un derecho para saber si lo hace con la intención de perjudicar a terceros. El jurista Lino Cornejo respalda esta objeción manifestando que no es posible penetrar en la región turbada del alma para averiguar la intención con que ha ejercitado su derecho la gente. En derecho, a nadie se le puede pedir cuenta de los móviles que lo impelen a ejercer su derecho. Sería difícil conseguir que la gente confiese que obró con la intención de dañar, ya que siempre le será posible alegar en su descargo algún interés particular. Se agrega a estos puntos de vista que sería sumamente peligrosos dar al juez la facultad de practicar esta investigación de carácter psicológico, ya que pueden derivarse de ella incertidumbre, inseguridades, $y$, consecuentemente, injusticias. Por todo lo

9 Luis Josserand. Op.cit. 
expuesto se considera que el criterio relacionado con "la intención de dañar" debe ser superado por resultar inseguro e ineficaz.

Otro criterio es el relacionado con la falta de un interés serio y legítimo que planea el tratadista Raymundo Saleilles. Según éste: "Un acto cuyo efecto sólo puede ser el perjuicio a otro, sin un interés serio y legítimo para quien ejercita su derecho, jamás constituirá uso lícito de ese derecho". Las objeciones que se formulan a esta tesis son: a) que no prescinde de adoptar una concepción primordialmente subjeriva, pues la medida de la utilidad de un acto está en relación al interés que tenga el sujeto que lo ejercita, por lo que Josserand la tachó como una fórmula utilitaria; b) que la fórmula es bastante vaga porque es difícil, en cada caso concreto, establecer cuándo un interés pueda ser tachado de ilegítimo y falto de seriedad; c) porque resulta ineficaz, ya que a cualquier sujeto le será fácil alegar un interés como móvil de su acto tachado como abusivo.

Esta fórmula, evidentemente, es más aceptable que la primera. Si bien el elemento "intención de dañar" no deja de funcionar, pero ya no es el elemento decisivo, pues "la falta de interés" es el que pasa al primer plano, quedando la intención de dañar como elemento subsidiario.

Si bien no da un concepto preciso del abuso del derecho contiene un elemento que unido al de la "intención de dañar", fue utilizado por Rippert para definir el acto abusivo como un "acto normal, en apariencia, pero realizado sin un fin útil y con intención de dañar" por lo que considerado como anormal "suscita la responsabilidad de su autor a pesar de su legalidad objetiva".

Otra tesis ha considerado el Abuso del Derecho como una desviación de su función social. Se basa en el criterio de León Duguit que tratando de eludir toda concepción abstracta y metafísica pretendió aplicar un método estrictamente positivo a la ciencia jurídica, negando la existencia del derecho subjetivo por ser un concepto individualista y puramente metafísico contrario a la realidad de los hechos sociales y jurídicos. Josserand, citando a Duguit en relación a este fundamento del abuso del derecho, dice que "en una sociedad organizada los pretendidos derecho subjetivos son derecho-funciones; deben mantenerse en el plano de la función a que corresponden; en caso contrario, su titular comete una desviación, un abuso del derecho o sea que el acto abusivo es el acto contrario al fin de la institución, a su espíritu y a su finalidad". 
Duguit fundamenta el derecho como función social manifestando que el hombre no tiene derechos, la colectividad tampoco lo tiene, pero todo hombre, en la sociedad, tiene cierta función que cumplir, cierta tarea que ejecutar y esto es, precisamente, el fundamento de la regla que se impone a todo; de donde resulta que todos los actos contrarios a esa función del individuo son socialmente reprimidos y los actos encaminados al cumplimiento de esa función son socialmente protegidos. El fundamento de la norma descansa en la necesidad de mantener coherentes los diferentes elementos sociales, lo que se consigue con el cumplimiento de la función social que le corresponde a cada individuo o cada grupo.

Los tratadistas franceses Henry y León Mazeaud objetan este criterio, opinando que si se le constriñe a un juez a determinar la función social de un derecho cualquiera, deberá salir de los dominios del Derecho para caer en los de la política. Dicen: "He aquí el peligro del criterio: ¿se hace un socialista la misma concepción del fin con que se ha concedido el derecho de propiedad que un adversario de Karl Marx? Evidentemente no. Es cierto que defender la doctrina del fin social de los derechos de ninguna manera significa inclinarse hacia el socialismo, pero importa constreñir a los jueces a contemplar el problema de la responsabilidad desde el ángulo de la política”. ${ }^{10}$

Se dice, también, que una tesis de esta especie se entronca con el positivismo que contempla al derecho como una función social, en lugar de considerarlo como una facultad o poder de los individuos, lo que puede llevar al extremo de negar los derechos subjetivos.

\section{Conclusión}

Frente a la diversidad de criterios para explicar el fundamento del acto abusivo, debemos tratar de extractar los elementos más adecuados para ofrecer un enfoque correcto con un planteamiento estrictamente jurídico. Solo se puede hablar de Abuso de Derecho cuando en su ejercicio se causa un daño a otro, a pesar de que ese ejercicio puede resultar impune en el derecho positivo por no aparecer limitado ese modo de ejercitar el derecho.

10 H. y L. Mazeaud. Tratado teórico y práctico de la responsabilidad civil. 1931. 
A pesar de las divergencias sobre el fundamento del Abuso del Derecho, se nota un fondo común que justifica su vigencia: el que ejercita su derecho de un modo socialmente reprobado por cuanto perjudica a tercero está obligado a sufrir las consecuencias de su ejercicio abusivo. Como bien dice el destacado jurista José León Barandiarán, el estado actual del progreso jurídico justifica que se consagre el principio del abuso del derecho, lo que nos permite preveer una situación de hecho que acontece en la vida real y le adscribe una consecuencia jurídica. Se objeta que el acto abusivo es simplemente un acto ejecutado sin derecho, lo que, como acota León Barandiarán lleva a considerar que la noción de abuso del derecho es una logomaquia por resultar contradictoria y absurda. El error de esta objeción estriba en que, como advierte Josserand citado por J. León Barandiarán, no se distingue la posibilidad de que un acto sea conforme a un derecho determinado $y$, no obstante contrario al derecho considerado en su generalidad y su totalidad objetivadora, cuando él no se utiliza conforme a la exigencia propia del derecho in genere.

\section{El arbitrio judicial}

De lo expuesto deducimos que no es imprescindible establecer una fórmula que condense lo que es el abuso del derecho. Cualquier fórmula puede resultar insuficiente o conducirnos a criterios erróneos. Hay que tratar de armonizar los intereses individuales y los sociales, usar nuestro derecho sin afectar a la moral, en armonía con las buenas costumbres y con los usos de tráfico jurídico. Y nada de esto se podría conseguir si encasillamos la labor del Juez en un marco estrecho y rígido. Por eso creemos que la solución más acertada para aplicar el principio del abuso del derecho está en el arbitrio judicial. Es decir, que la ley no determinará cuándo se ejercita un derecho en forma abusiva. Debe ser el Juez el que en cada caso concreto, evaluando la forma y circunstancia en que se ejerce una facultad legal, dirá si hay o no abuso del derecho. Se ha argumentado que al adoptar esta solución hay el peligro de que al dejar al juez la apreciación de un caso de abuso de derecho, es poner en sus manos un instrumento de arbitrariedad, pues lo que la ley no define debe resolver el juez aplicando su criterio personal. 
Como dice Bibiloni: "Eso que la ley no ha acertado a definir lo encontrará el Juez. Cada Juez lo verá según su criterio moral, político o económico. Lo que no saben los juristas, puesto que sólo dan fórmulas generales, eso lo sabrá el Juez".

Esta objeción importa confundir arbitrio judicial con arbitrariedad. La arbitrariedad significaría que el juez expida una resolución sin tener en cuenta la ley, ni la doctrina ni los principios de derecho o ateniéndose a una interpretación muy personal y capciosa de la ley. En cambio, el arbitrio judicial significa que el juez se sujeta a una norma, a un principio doctrinario y toma en cuenta el criterio de equidad. Recordemos que nuestro Código Civil en el Arr. XXIII del Título Preliminar establece que el juez debe aplicar los principios de derecho en caso de deficiencia de la ley, y que en el caso del Art. $1322^{\circ}$ le da facultad para graduar la culpa teniendo en cuenta las circunstancias de persona, lugar y tiempo. Que, asimismo, faculta al juez para aplicar el criterio de equidad para fijar el monto de la reparación civil en el caso de los Arts. $1140^{\circ}$ y $1143^{\circ}$. Como bien dice el citado jurista nacional doctor José León Barandiarán: "en toda dimensión del derecho está irremisiblemente presente la atención de justicia versus seguridad. Si se implantase una actitud que velase únicamente por la seguridad, de modo exagerado, muchas soluciones del derecho tendrían que desaparecer. Por ejemplo, la nulidad del acto por vicios de consentimiento. El juzgamiento, en cada caso, tiene algo de individualizador". ${ }^{11}$

En conclusión: el arbitrio judicial importa la aplicación de una norma, un principio de la doctrina jurídica a la solución del caso que el Juez resuelve con criterio de justicia y equidad. Creemos acertado que se haga uso del arbitrio judicial para la constatación del abuso del derecho en cada caso.

\section{El abuso del derecho en la legislación comparada.}

Las legislaciones civiles codificadas en relación con el abuso del derecho han adoptado diversos criterios, pues unos han seguido la corriente objetiva y otros la subjetiva.

11 José León Barandiarán. "Comentarios al Código Civil Peruano". Rev. de D. y Ciencias Políticas. Año XII. No 2. 
En Francia no se ha elaborado una fórmula legislativa que contemple, en forma especial el abuso del derecho, pero es el país donde se ha dado mayor número de aplicaciones jurisprudenciales de ese principio lo que ha obedecido al contenido amplio de los artículos $1382^{\circ}$ y $1383^{\circ}$ del Código de Napoleón. El Art. 1382 dice: "Cualquier hecho del hombre que cause al otro un daño, obliga a repararlo a aquél por cuya culpa se ha producido" y el $1383^{\circ}$ expresa que: "Es responsable del daño quien lo causó no sólo por su hecho, sino también por su negligencia o por su imprudencia".

Prevalece, pues, en Francia la orientación subjetiva, pues las normas referidas obligan a tener en cuenta el requisito de la culpa.

El Código Civil belga también se inspiró en el criterio del francés. Pero fue en Alemania donde el principio del abuso del derecho tuvo una clara expresión legislativa. Tal se deduce del Landrecht Prusiano de 1794 que en sus artículos $27^{\circ}$ y $28^{\circ}$ legisla el abuso del derecho de propiedad al manifestar que "Art. $27^{\circ}$ : Nadie puede abusar de su propiedad para lesionar el derecho de otro y causarle un perjuicio. Art. 28: El abuso de la propiedad es todo uso que por su naturaleza no pueda tener otro fin que el de lesionar a otro". Otra disposición relacionada con el abuso del derecho es el Art. 26० que dice: "El que ejerce en sus límites propios un derecho no está obligado a reparar el daño que resulta para otro. Pero se debe reparación cuando resulta de las circunstancias que, entre varios modos posibles de ejercicio de su derecho, ha elegido aquel que es dañoso para otro, con la intención de perjudicarlo". Esta disposición adopta un criterio subjetivo, en relación al abuso del derecho que se le hace consistir en la intención de perjudicar.

Más fue en el Código alemán en 1896 donde se introdujo un precepto claro referente al abuso del derecho en su Art. $226^{\circ}$ que dice: "El ejercicio de un derecho no es permitido cuando no puede tener otro objeto que causar daño a otro". Según este texto la noción del abuso del derecho se hace consistir en el ejercicio de un derecho que sólo tiene por objeto causar daño a tercero. De su redacción deducimos que el criterio que preside la elaboración de dicho precepto es la intencionalidad. La institución resulta vinculada a la intención de perjudicar, como un hecho calificante reprochable. Tiene, pues, una orientación subjetiva.

El Código Civil austríaco de 1916, reformado el $1^{\circ}$ de enero de 1917 en su Art. $1295^{\circ}$ establece: "El que causa intencionalmente un 
daño de modo que hiera las buenas costumbres es igualmente responsable; no lo es, sin embargo, si el daño fue causado por el ejercicio de un derecho, salvo si el ejercicio de ese derecho tiene manifiestamente el fin de perjudicar a otro". Como se desprende de la última parte de la disposición, tiene ésta una orientación subjetiva. Igual orientación tiene el Código Civil italiano de 1942 en su Art. $833^{\circ}$ y el Código Polaco de las Obligaciones en su Art. 137\%.

El Código Civil suizo de 1907 también denominado Código Federal Suizo, introduce un criterio original al tratar del abuso del derecho. Si bien el anteproyecto de 1900 se refería al abuso del derecho de propiedad (Art. 644\%) que se le hace consistir en su ejercicio con la sola intención de perjudicar a otro, el Código Civil de 1907 incorporó la doctrina del abuso del derecho en su artículo II, que dice: "Cada uno está obligado a ejercer sus derechos y a cumplir sus obligaciones según las reglas de la buena fe. El abuso manifiesto de un derecho no está protegido por la ley". Como se ve la amplitud del principio es vasta y comprende cualquier clase de derechos: privados o públicos.

Virgilio Rossel comenta que lo decisivo no es la intención de dañar sino el elemento subjetivo del ejercicio de un derecho en forma contraria a las reglas de la buena fe, sin que ese ejercicio implique la persecución de un interés digno de la protección legal. Sigue comentando dicho tratadista "No se trata del elemento subjetivo intención de abusar, sino del elemento objetivo, del ejercicio del derecho contrariando las reglas de la buena fe y sin que ese ejercicio implique la persecución de un interés digno de protección legal; el demandante debe probar que el abuso del derecho que ejercita su contrario le causa perjuicio.

Como vemos el Código suizo no define el abuso del derecho, pero da un criterio para determinarlo: ejercitar un derecho o cumplir una obligación contrariando las reglas de la buena fe, que no es sino la aplicación de la regla moral como límite de la actividad jurídica. El abuso debe ser manifiesto tanto por el perjuicio ocasionado cuando por la falta de un interés legítimo en el tirular que haga palpable la finalidad torcida del agente. El Consejo Federal Suizo en su mensaje de 23 de mayo de 1904, refiriéndose al Art. II del Código Civil decía: "Hemos creado una especie de recurso extraordinario que debe conseguir el respeto a la justicia, en provecho de aquellos que sufrirían con el abuso evidente que un tercero hiciera de su derecho, cuando los medios ordinarios fueron insuficientes para protegerlo". 
No olvidemos que la referida disposición del Código Civil suizo de 1907 fue la que inspiró al Dr. Juan José Calle para la incorporación del principio del abuso del derecho en su ponencia del Título Preliminar que propuso a la Comisión Reformadora del Código Civil.

José León Barandiarán al comentar este dispositivo del Código Civil suizo dice: "Se trata de un complejo objetivo, en que han de apreciarse todas las circunstancias vinculadas al hecho, para saber si hubo mala fe en el agente".

El Código Civil ruso del $1^{\circ}$ de enero de 1923 en el Art. $1^{\circ}$ de la Parte General dice, que los derecho civiles están tutelados por la ley, salvo los casos en que sean ejercitados contrariamente a su objetivo económico o social lo que quiere decir que para el Código Civil soviético el abuso del derecho consiste en ejercer un derecho contrariando el objetivo económico y social. Evidentemente esta formulación corresponde a una nueva concepción del Estado y del Derecho, en el caso de Rusia soviética se asienta sobre las bases del materialismo histórico. Como dice Spotta" "La teoría objetiva y funcional, es aceptada, entonces, con amplitud: sólo se es titular de derecho y obligaciones civiles en el campo patrimonial, ya que el derecho de familia es objeto de un Código especial, en tanto queden cumplidos los fines estatales, o sea en cuanto no se lesione el espíritu de la legislación concebido en forma bien distinta al de la legislación prevaleciente en los paises de régimen capitalista". Según el tratadista Angel Gustavo Cornejo, la fórmula del abuso del derecho en el Código ruso responde a la orientación del Estado de subordinar el orden jurídico a la realización de su fin.

El Código Civil de México de 1932 circunscribe la doctrina del abuso del derecho al derecho de propiedad, cuando en su Art. 840 dice que no es lícito ejercitar el derecho de propiedad de manera que su ejercicio no de otro resultado que causar un perjuicio a tercero sin utilidad para el propietario.

El Código Civil de Venezuela de 1942, en la segunda parte del Art. $1185^{\circ}$ dice que "Debe igualmente reparación quien haya causado un daño a otro, excediendo en el ejercicio de su derecho los límites fijados por la buena fe o por el objeto en vista del cual le ha sido conferido ese derecho", lo que hace consistir el abuso del derecho en ejercerlo con-

12 Alberto G. Spotta. Tratado de Derecho Civil. Edit. de Palma, 1947. 
trariando las reglas de la buena fe o del objeto con el que se ha establecido ese derecho, causando un daño con ejercitar el derecho en tal forma.

El Código Civil de Brasil de 1916 no contiene disposición especial sobre el abuso del derecho, pero hace referencia tangencial a esa figura jurídica en su Art. $160^{\circ}$ referente a los actos ilícitos. Clovis Bevillacqua, jurista brasileño, al comentar el primer inciso de ese artículo dice: "El ejercicio de un derecho cuando no es regular, cuando no se conforma con su destino económico y social, cuando ofende las exigencias étnicas, es considerado abusivo y acarrea responsabilidad". Para concluir manifestando que "Derecho abusivo es el derecho que teniendo una apariencia legítima comporta un desvío del orden jurídico".

El Código Civil de España, vigente desde mayo de 1974 en su Art. $7^{\circ}$ contiene una disposición explícita sobre el abuso del derecho; dice: "Los derechos deberán ejercitarse conforme a las reglas de la buena fe. La ley no ampara el abuso del derecho o el ejercicio antisocial del mismo. Todo acto u omisión que por la intención de su autor, por su objeto o por las circunstancias en que se realice sobrepase manifiestamente los límites normales del ejercicio de un derecho con daño para tercero, dará lugar a la correspondiente indemnización y a la adopción de las medidas judiciales o administrativas que impidan la persistencia en el abuso"13. Como podemos observar toma en cuenta las reglas de la buena fe que son normas conforme a las que debemos obrar al ejercitar nuestros derechos. Luego tipifica el derecho como el ejercicio antisocial del mismo lo que denota el criterio objetivo y nos hace recordar la teoría de Saleilles para quien el abuso del derecho consiste en el ejercicio anormal del derecho, contrario a su destino económico y social. Si en un momento dado el titular ejercita su facultad contrariamente a la télesis social del derecho, está abusando de él. Sin embargo, debemos anotar que no descarta la intención del autor, a que alude la última parte de la disposición acotada (Art. $7^{\circ}$ ), como uno de los elementos para configurar el abuso del derecho. Para la mala intención no es suficiente para encontrar el abuso; debe tenerse en cuenta también "objeto" o "las circunstancias" en que se realice el acto. Nos hace pensar que tal fórmula acoge el criterio ecléctico de José Calvo Sotelo, ya que el propasamiento subjetivo debe trascender al exterior, es decir que

13 Versión proporcionada por el Dr. Julio Ayasta Gonzáles. 
exista cierta "impureza objetiva" como denominaba el tratadista español. Impureza objetiva que debe traducirse en un daño para tercero. Dice el citado jurista que "todo derecho subjetivo posee dos valores de actuación; de un lado es prerrogativa jurídica, de otro lado todo derecho es una fuerza económica-social al mismo tiempo que categoría de índole moral". Según el Código español el ejercicio anormal de un derecho, que causa daño a tercero, dará lugar a la respectiva indemnización y a la adopción de las medidas "judiciales o administrativas" que impidan la persistencia del abuso. Por lo demás, la fórmula es demasiado amplia.

\section{El Abuso del Derecho en la legislación peruana}

El Dr. Juan José Calle, miembro de la "Comisión Reformadora del Código Civil Peruano" nombrada por Resolución Suprema de 26 de agosto de 1922, propuso la necesidad de fijar un plan de trabajo conforme al que cada uno de los miembros de esa Comisión tendría a su cargo determinadas materias del Proyecto de Código Civil que debía sustituir al vigente. Aprobada esa ponencia se le asignó la tarea de ocuparse del Título Preliminar, cuyo proyecto presentó en la sesión del 7 de febrero de 1923. De los 21 artículos que lo conformaban, el Art. VI decía: "A nadie puede prohibirse la acción que no está prohibida por la ley; pero ésta no protege el manifiesto abuso del derecho". La ponencia era novedosa, pues por primera vez se proponía en la legislación civil peruana un dispositivo que acogía la teoría del abuso del derecho, en forma concreta. En la sesión del 21 de febrero de 1923 se puso en discusión la ponencia del Dr. Calle y el Art. VI motivó un interesante debate en el que, luego de la fundamentación del Dr. Calle, intervinieron los Drs. Olaechea, Oliveira y Solf, miembros de la Comisión, quienes expusieron sus puntos de vista. Acordaron reservar el debate sobre este punto que se reabrió posteriormente como constan de las actas insertas en el fascículo VI. En esta oportunidad, el ponente Dr. Calle fundamentó su proyecto apoyándolo en lo expuesto por el tratadista francés Josserand. Discutido ampliamente el punto por todos los miembros de la Comisión, se acordó suprimir la primera parte del proyecto del Dr. Calle por considerarse que importaba una repetición del principio consagrado por el Art. $24^{\circ}$ de la Constitución de 
1920 en vigencia. Además se eliminó el vocablo "manifiesto" por considerarlo innecesario.

Quedó definitivamente incorporada la disposición en el Art. III del Título Preliminar del Proyecto, en la siguiente forma: "Art. III.- la ley no ampara el abuso del derecho" redacción que se mantuvo sin ninguna variante en el Art. II del Título Preliminar del Código Civil promulgado el 30 de agosto de 1936.

Anotamos que el antecedente legal del artículo referido se encuentra en el artículo II del Código Federal Suizo de 1907 que hemos comentado anteriormente.

La ubicación del artículo en el Título Preliminar de nuestro Código Civil es acertada ya que está en las disposiciones de carácter general aplicables a la economía del código. Se trata de un principio invívito en diversas instituciones reguladas por el referido cuerpo legal, por lo que resulta básico para el Juez que debe tomar en cuenta al aplicar una disposición legal.

Se ha criticado el texto del artículo por considerarlo diminuto ya que su formulación sólo contiene una declaración abstracta, sin carácter normativo. Se dice que no establece el criterio que fundamenta el abuso del derecho. El Dr. Lino Cornejo manifestó que no contiene una base sólida para caracterizar la figura, pues su formulación abstracta la hace de contenido indefinible. Coincidimos con la ilustrada opinión del destacado jurista Dr. José León Barandiarán, al desechar la objeción, por cuanto la disparidad de criterios en cuanto a su fundamentación teórica hace aconsejable que tal discrepancia no se refleja en el texto legal.

El criterio está sujeto a variaciones, de acuerdo con la evolución de la sociedad. Por eso sería inconveniente formular un texto determinado. Como dice el citado jurista "basta con insertar simplemente el mandato preceptivo". La cátedra y la academia, por un lado, y la jurisprudencia por otro, establecerán en cada caso el criterio informante para saber cómo y cuándo funciona la regla.

Puede ocurrir que el concepto científico del abuso del derecho evolucione y, entonces, el juzgador no podría aplicar este principio por cuanto su formulación ortodoxa no permitiría adaptarlo al nuevo criterio. Por eso creemos que basta con enunciar la norma; su fundamentación y explicación racional debe quedar librada a la interpretación doctrinaria y el alcance y dimensión de su interpretación debe quedar a cargo de la jurisprudencia. 
Adoptar una fórmula estrecha importaría caer en casuísmos que quitarían toda su bondad al principio.

Lo expuesto nos lleva a la conclusión de que hay que dar amplitud al Juez para aplicar el principio del abuso del derecho. No se le debe encasillar dentro del criterio objetivo ni dentro del criterio subjetivo. La intención, la finalidad, del acto, la buena fe, las costumbres y los usos del tráfico, la utilidad, la equidad son elementos que debe tener en cuenta el Juez para apreciar correctamente si el acto es abusivo.

Es innegable que se le impone una delicada tarea al juzgador.

Pero como dice el Dr. Luis A. Eguiguren "la fórmula que hemos adoptado es, evidentemente, vaga; pero siendo una teoría en formación, porque la vida la enriquece diariamente a través de la jurisprudencia, no sabríamos como podría tomar la categoría de dogma legal y claro".

Por lo demás, nuestro Código Civil de 1936 contiene una serie de preceptos en que el principio del abuso del derecho tiene su confirmación.

Tales los Arts. $1136^{\circ}$ y $1137^{\circ}$ de los que éste último, que tiene su antecedente en el Art. $160^{\circ}$ de Código Civil brasileño, no considera actos ilícitos los practicados en el ejercicio regular de un derecho, el $163^{\circ}$ que faculta a la mujer a no aceptar la decisión del marido cuando ésta constituya un abuso del derecho, el $861^{\circ}$ que reconoce al tercero afectado o amenazado por un daño que se deriva del ejercicio abusivo de un derecho, que se restituya al estado anterior o que se adopten las medidas del caso, sin perjuicio de la indemnización por el daño sufrido; el Art. $989^{\circ}$ que responsabiliza al acreedor que abusa de la prenda por su deterioro o pérdida; el Art. $1138^{\circ}$ sobre agobio del deudor, el Art. $1529^{\circ}$, inciso 3 que permita la rescisión del contrato de locación y conducción si el arrendatario abusa de la cosa; el inc. $2^{\circ}$ del artículo $1595^{\circ}$ que responsabiliza al comodatario por el menoscabo o ruina proveniente del abuso por el no empleo de la cosa de acuerdo con su naturaleza o con el pacto; el Art. $1637^{\circ}$ considera abuso del derecho del mandatario emplear en su provecho lo que recibe del mandante, estando obligado a resarcir el daño.

Basta con los preceptos que a manera de ejemplos, citamos, para demostrar lo que aseveramos al comienzo de este acápite.

El Abuso del Derecho en el proyecto del Código Civil. En el Proyecto del Código Civil del Dr. Felipe Osterling Parodi presentó a con- 
sideración del Poder Legislativo, bajo el epígrafe "Principios Generales", en el Art. VI del Título Primero se dice: "La ley no ampara el abuso del derecho. Se incurre en tal abuso, cuando en el ejercicio de su derecho, el titular se excede manifiestamente de los límites de la buena $\mathrm{fe}$, de modo que dicho ejercicio no se compatibiliza con la finalidad institucional y la función social en razón de las cuales se ha reconocido el respectivo derecho. El interesado puede exigir que sean adoptadas las medidas adecuadas para evitar o suprimir el abuso, sin perjuicio de la indemnización que le corresponda".

Como se ve, en contraposición con la redacción escueta del Art. II del Título Preliminar del Código Civil vigente, la que emplea ese proyecto es explícita y algo ampulosa, posiblemente en el afán de volver al sistema de las definiciones utilizado en el Código Civil de 1852, como admiten algunos miembros de la Comisión constituida por D.S. No95, sistema que adoptaron según afirma, con el objeto de "aclarar el sentido de las normas".

Advirtiendo las tachas y objeciones formuladas por juristas y abogados, ya individualmente o agrupados en instituciones, la Comisión Revisora constituida de acuerdo con la Ley No 23403, modificó la redacción del proyecto Osterling (que resulta un anteproyecto), en cuanto se refiera al Abuso del Derecho, en la siguiente forma: "Art. II.La ley no ampara el abuso del derecho. El interesado puede exigir la adopción de las medidas necesarias para evitar o suprimir el abuso y, en su caso, la indemnización que corresponda".

Dicha disposición está en el título Preliminar precedida por el título Principios Generales.

Como observamos, el Proyecto de la Comisión Revisora presidida por el Dr. Alva Orlandini, mantiene la fórmula del Código Civil vigente en cuanto declara que la ley no ampara el abuso del derecho. Elimina la definición que de tal figura hizo el anteproyecto Osterling. Y adopta de éste la última parte referente al uso de las medidas necesarias para evitar o suprimir el abuso y exigir, en su caso, la indemnización respectiva.

La exclusión del fundamento, enunciado en el anteproyecto, nos parece acertada. La discrepancia de criterios para la fundamentación teórica del abuso del derecho, que ha motivado sendas discusiones de los tratadistas, demuestra las inconveniencias de adoptar uno de estos criterios en el texto legal que debe ser simplemente declarativo del 
principio, tal como se incorporó por la Comisión Codificadora en el Código Civil de 1936 y que, según aparece de la Exposición de Motivos de dicho cuerpo legal, fue propuesta por el ilustre jurisconsulto Dr. Manuel Augusto Olaechea, quien considera que cualquiera aclaración sobre el fundamento de la institución constituía un "exceso del lenguaje". Como dice el tratadista Dr. J. León Barandiarán "se trata de una norma regulativa, informante general, de un sentido plástico y sinóptico, que evita amarrar, atar, ligar, sojuzgar el criterio a una predeterminada fórmula ortodóxa". Como anota el mismo jurista, "el concepto científico mismo del abuso del derecho puede evolucionar y el juzgador quedaría a la zaga, tributario del concepto impuesto de antemano por el legislador".

En la última parte del artículo referido hay una indicación acerca de las medidas que puede adoptar el tercero -a quien impropiamente se le denomina "interesado"- para contrarrestar el abuso del derecho y, en su caso, pedir la indemnización correspondiente. El antecedente legal de esta parte se encuentra en la última parte del Art. $7^{\circ}$ del Código Civil español de 1974. Producido el abuso del derecho, la persona afectada por el mismo se opondrá a la pretensión del actor, exigiendo la adopción de las medidas que sean necesarias para evitar o suprimir el abuso. Tal oposición, considera el Dr. León Barandiarán, que es una especie de "excepto dolis generalis" que debe operar como supletorio de cualquier otro medio o recurso utilizable por el sujeto pasivo de la relación jurídica. La prueba incumbiría al excepcionante y serviría para fundamentar el fallo del Juez que dictará las medidas para evitar o suprimir el abuso si constata que el ejercicio del derecho se hace en forma irregular o excesiva. Subsidiariamente puede derivarse de ese ejercicio la obligación de indemnizar al tercero damnificado.- A manera de recapitulación diremos que lo importante es que se aplique el principio del Abuso del Derecho en la prácrica, ya que son contados los casos en que se le ha dado vigencia efectiva, a pesar de estar incorporado en nuestra legislación desde 1936. 